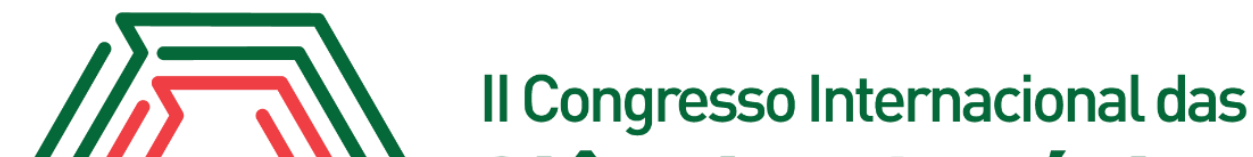 Ciências Agrárias COINTER - PDVAgro 2017
}

\section{INCIDÊNCIA DE FUNGOS EM SEMENTES DE FEIJÃO-CAUPI PROCEDENTES DA AGRICULTURA FAMILIAR}

\author{
Apresentação: Pôster
}

Jane Clésia Silva dos Santos ${ }^{1}$; Alciele da Silva Leite ${ }^{2}$; Abraão Rodrigues de Almeida ${ }^{3}$; José Miguel da Silva Neto ${ }^{4}$; Denise de Santana Silva ${ }^{5}$

\section{Introdução}

No Brasil, o feijão-caupi (Vigna unguiculata L. Walp.) é uma cultura que desempenha papel fundamental na produção agrícola por ser o principal componente na alimentação da população das regiões Norte e Nordeste. É uma cultura de ciclo curto, pouco exigente em fertilidade e que se adapta bem às condições climáticas com altas temperaturas (Bertini et al., 2009; Rego et al., 2015).

A qualidade sanitária para a semente do feijoeiro é um dos fatores mais importantes para o sucesso da produção, pois muitas doenças que atacam a cultura são transmissíveis pela semente e causam a deterioração durante o armazenamento (MACHADO, 1988). Sementes vigorosas e livres de patógenos de cultivares melhorada são necessárias para o aproveitamento máximo dos efeitos de irrigação, adubação e defensivos agrícolas. Portanto, sementes produzidas de forma correta, desde o campo até armazenamento, surgem como uma alternativa para agricultura familiar (BARBOSA; GONZAGA 2012).

A qualidade da semente é expressa pela interação de quatro componentes: genético, físico, fisiológico e sanitário. O componente sanitário refere-se ao efeito deletério provocado pelos insetos

\footnotetext{
${ }^{1}$ Bacharelado em agronomia, Instituto Federal de Ciência e Tecnologia de Pernambuco Campus-Vitória de Santo Antão, janeclsia@gmail.com

${ }^{2}$ Bacharelado em agronomia, Instituto Federal de Ciência e Tecnologia de Pernambuco Campus-Vitória de Santo Antão, alcieleleite@gmail.com

${ }^{3}$ Bacharelado em agronomia, Instituto Federal de Ciência e Tecnologia de Pernambuco Campus-Vitória de Santo Antão, abraaoalmeida98@gmail.com

${ }^{4}$ Bacharelado em agronomia, Instituto Federal de Ciência e Tecnologia de Pernambuco Campus-Vitória de Santo Antão, josemiguelifpe@gmail.com

${ }^{5}$ Mestre Fitossanidade, Instituto Federal de Ciência e Tecnologia de Pernambuco Campus-Vitória de Santo Antão, denise.santana@vitoria.ifpe.edu.br
} 
e microrganismos associados às sementes, desde o campo de produção até o armazenamento (WANDER 2005). Diante do exposto, o objetivo deste trabalho visou analisar a qualidade sanitária de sementes armazenadas de feijão-caupi produzidas pelos agricultores familiares.

\section{Fundamentação Teórica}

A cultura do feijão-caupi (V.unguiculata L. Walt) tem sido atacada por vários patógenos, os quais apresentam influência negativa na produtividade e na qualidade da produção. Entre esses patógenos destacam-se os fungos, que possuem ampla diversidade de espécies patogênicas, estando presentes em diversos habitats e colonizando patogenicamente várias partes vegetais do feijoeiro (ATHAYDE SOBRINHO, 2005).

Há uma grande disponibilidade de trabalhos, na literatura, enfatizando a transmissão de agentes causais de importantes doenças em diversas espécies vegetais. No entanto, a literatura relativa à sanidade de sementes de caupi, nas condições do Brasil, é escassa. Certa ênfase pode ser dada aos trabalhos de Barros e Menezes (1981), Oliveira e Bolkan (1981), Araújo et al. (1985) e Choudhury (1987), onde os autores destacaram a ocorrência de diversos fungos em associação com feijão-caupi.

Os fungos presentes nas sementes armazenadas são tradicionalmente divididos em dois grupos: de campo e de armazenamento. Os primeiros invadem as sementes ainda no campo, requerendo para o seu crescimento, umidade relativa em torno de 90-95\%. O tempo de sobrevivência desses fungos nas sementes está diretamente relacionado com as condições de ambiente do armazém. Os fungos de armazenamento, por sua vez, estão presentes nas sementes recém-colhidas, geralmente em porcentagens muito baixas. São capazes de sobreviver em ambiente com baixa umidade, proliferando em sucessão aos fungos de campo e causando a deterioração das sementes (TANAKA et al., 2001).

\section{Metodologia}

A presente pesquisa apresenta natureza quantitativa do tipo experimental utilizando recursos e técnicas estatísticas transformando informações em números para uma melhor compreensão dos resultados. Para Mattar (2001), a pesquisa quantitativa permite através de uma análise representativa de dados validar hipóteses utilizando dados estatísticos orientado para um resultado final.

O experimento foi conduzido no Laboratório de Fitopatologia do Instituto Federal de 
Educação, Ciência e Tecnologia de Pernambuco (IFPE) no Campus Vitória de Santo Antão, onde foi avaliada a incidência de fungos presentes nas sementes de feijão-caupi procedentes de assentamentos e comunidades rurais dos municípios de Lagoa do Itaenga e Moreno-PE, Brasil, que foram indicados pelos conselhos rurais e órgãos de assistência técnica responsável e por meio da aplicação de um questionário semi-estruturado buscaram-se informações sobre a cultura, pragas e doenças.

Para o teste de sanidade foram coletadas 18 amostras de feijã-caupi, onde a princípio foi feita a desinfestação superficial com hipoclorito de sódio a $2 \%$ por três minutos, lavadas com água destilada esterelizada (ADE) e secas ao ar livre. O método utilizado foi o do papel filtro (blotter test), conforme descrito por Neergaard (1979). Foram utilizadas quatro repetições com 25 sementes em cada caixa plástica gerbox, totalizando 100 sementes, sendo colocadas sobre tripla camada de papel filtro esterelizadas e umedecidas com água destilada e esterilizada (ADE) na proporção de 2,5 vezes o peso do papel. Em seguida as sementes foram incubadas a temperatura de $20^{\circ} \mathrm{C}$, em regime de 12 horas de luz. Após o período de incubação as sementes foram examinadas com auxílio de um microscópio óptico para determinação da presença ou ausência de fungos.

O delineamento experimental foi inteiramente casualizado (DIC), onde os dados foram submetidos a uma estatística descritiva em que houve a interpretação e a apresentação de dados numéricos através da porcentagem de incidência de fungos presentes nas sementes de feijão-caupi.

\section{Resultados e Discussões}

$\mathrm{Na}$ análise sanitária das sementes de feijão-caupi, tanto na cidade de Lagoa de Itaenga quanto em Moreno foram identificados a incidência de fungos nas sementes de feijão-caupi, sendo eles Aspergillus sp. (29,9\%), Cladosporium sp. (0,11\%), Colletotrichum sp. (0,6\%), Fusarium sp. (0,6\%), Penicillium sp (0,5\%), Rhizopus (1,75\%), tabela 1. Pode-se observar que tanto fungos de armazenamento quanto de campo se estabeleceram nas sementes antes da colheita e depois, ou seja, no período do seu crescimento, maturação e conservação das sementes. 
Tabela 1: Incidência de gêneros de fungos associados às sementes de feijão-caupi procedentes da agricultura familiar dos municípios de Lagoa de Itaenga e Moreno (\%). Fonte: Própria

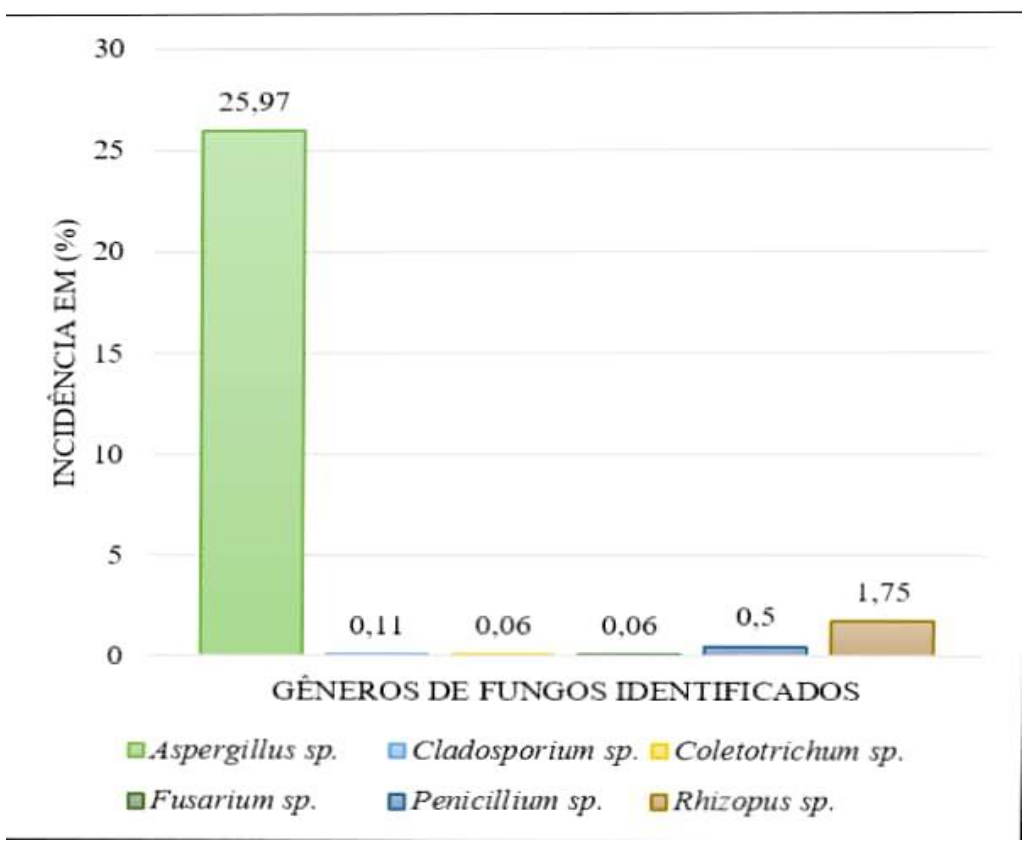

Após as sementes serem colhidas e armazenadas, as mesmas ficam sujeitas a invasão por um grupo de fungos designados como de armazenamento, e os principais gêneros observados foram Aspergillus sp., e Penicillium sp., sendo os danos causados por estas espécies variáveis, como perda de germinação, aumento da taxa de ácidos graxos, descoloração da semente, alterações bioquímicas, produção de toxinas danosas ao homem e a outros animais e redução do peso seco das sementes (TORRES e BRINGEL, 2005). Segundo Perez et al. (2007), o nível de qualidade de lotes de sementes está estreitamente correlacionado com a qualidade sanitária. Já os fungos de campo como Cladosporium sp., contaminam os grãos durante o cultivo por estes requererem ambiente com umidade relativa superior a $80 \%$.

\section{Conclusões}

Seis gêneros de fungos foram identificados nas sementes de feijão-caupi dos agricultores e agricultoras dos municípios de Lagoa de Itaenga e Moreno, onde apresentaram Aspergillus sp., com maior incidência $(27,9 \%)$ e com menor incidência Colletotrichum sp. $(0,6 \%)$, Fusarium sp. $(0,6 \%)$ 
respectivamente, pois pode-se concluir que com uma simples avaliação sanitária possibilita-se a identificação de problemas ocorridos desde a fase de campo até o armazenamento.

\section{Referência}

ATHAYDE SOBRINHO, C. DOENÇAS FÚNGICAS E BACTERIANAS. In: FREIRE FILHO, F.R; LIMA, J. A. A. RIBEIRO, V.Q. Feijão Caupi: Avanços tecnológicos. Brasília-DF: EMBRAPA, 2005.

ARAÚJO, E.; BARROS, S. T. B.; BOLKAN, H. A.; MENEZES, M.; OLIVEIRA, S. M. A.; CHOUDHURY, M. M.; TANAKA, M. T. B.; ZIEMBOWICZ, J. A. A. Qualidade sanitária e fisiológica de sementes de feijão-caupi (Vigna unguiculata (L.) Walp). São Luís, 2006. p.20. DISSERTAÇÃO (Pós graduação em Agroecologia). Departamento de Pós graduação, UEMA, 2006.

BARBOSA, F. R.; GONZAGA, A. C. O. FEIJÃO NO BRASIL. EMBRAPA. Informações técnicas para o cultivo de feijoeiro-comum na Região Central-Brasileira: 2012-2014. Disponível em: <http://www.cnpaf.embrapa.br/tranferencia/informacoestecnicas/publicacoesonline/seriedocumento s_272. pdf >. Acesso em: 10 de outubro de 2017.

BERTINI, C. H. M.; REGO, F. A. Qualidade sanitária de sementes salvas de feijão-caupi utilizadas pelos agricultores do Rio Grande do Norte. Revista de Ciências Agrárias Amazonian Journal, v.59, n.1, p. 60-65, 2009.

MACHADO, J. C. PATOLOGIA DE SEMENTES-FUNDAMENTOS E APLICAÇÕES. Brasília, MEC/ESALQ/FAEPE. p.106, 1988.

MATTAR, F. N. PESQUISA DE MARKETING. 3. ed. São Paulo: Atlas, 2001.

NEERGAARD, P. SEED PATHOLOGY .LONDON: The Mac Millan Press, 1979. v 2.

PEREZ, M. A.; CARVALHO, A.; MAIA, M. S. NÍVEL DE INFECCIÓN FÚNGICA NATURAL A LA CALIDAD DE SEMILLAS DE MANI. Revista Brasileira de Sementes, Brasília, v. 29, n. 2, p. 53-59, 2007.

TORRES, S. B.; BRINGEL, J. M. M. Avaliação d qualidade sanitária e fisiológica de sementes de feijão-macassar. Caatinga, Mossoró, v.18, n.2, p.88-92, 2005.

WANDER, A. E. CULTIVO DO FEIJÃO DA PRIMEIRA E SEGUNDA SAFRA NA REGIÃO SUL DE MINAS GERAIS. EMBRAPA. Disponível em:

http://sistemasdeproducao.cnptia.embrapa.br/FontesHTML/Feijao/FeijaoPrimSegSafraSulMG/psem entes.htm. Acesso em 10 de outubro de 2017. 